\title{
SATELLITE IMAGERY
}

The use of satellite imagery and its interpretation has become of increasing interest to the glaciologist over the last few years. Frequently, satellite images are used by glaciologists to illustrate or even demonstrate specific points in their papers. For this reason, it is particularly important that the reproduction of these illustrations is as good as can be achieved technically. In certain cases where the original tapes are still available, the recently developed enhancement techniques can achieve remarkably convincing results. But, regrettably, there are particular instances where the original tapes have deteriorated so severely that only existing photographic images are available for reproduction. Basically, there is no substitute for ground truth in the ultimate decision on whose interpretation is correct!

Figure 2 of the paper by N.F. McIntyre (Journal of Glaciology, Vol. 31, No. 107, p. 35) failed to reach an acceptable standard of reproduction and, since it has become the central feature of subsequent correspondence (see preceding pages), it is reproduced more satisfactorily here for the benefit of interested glaciologists.

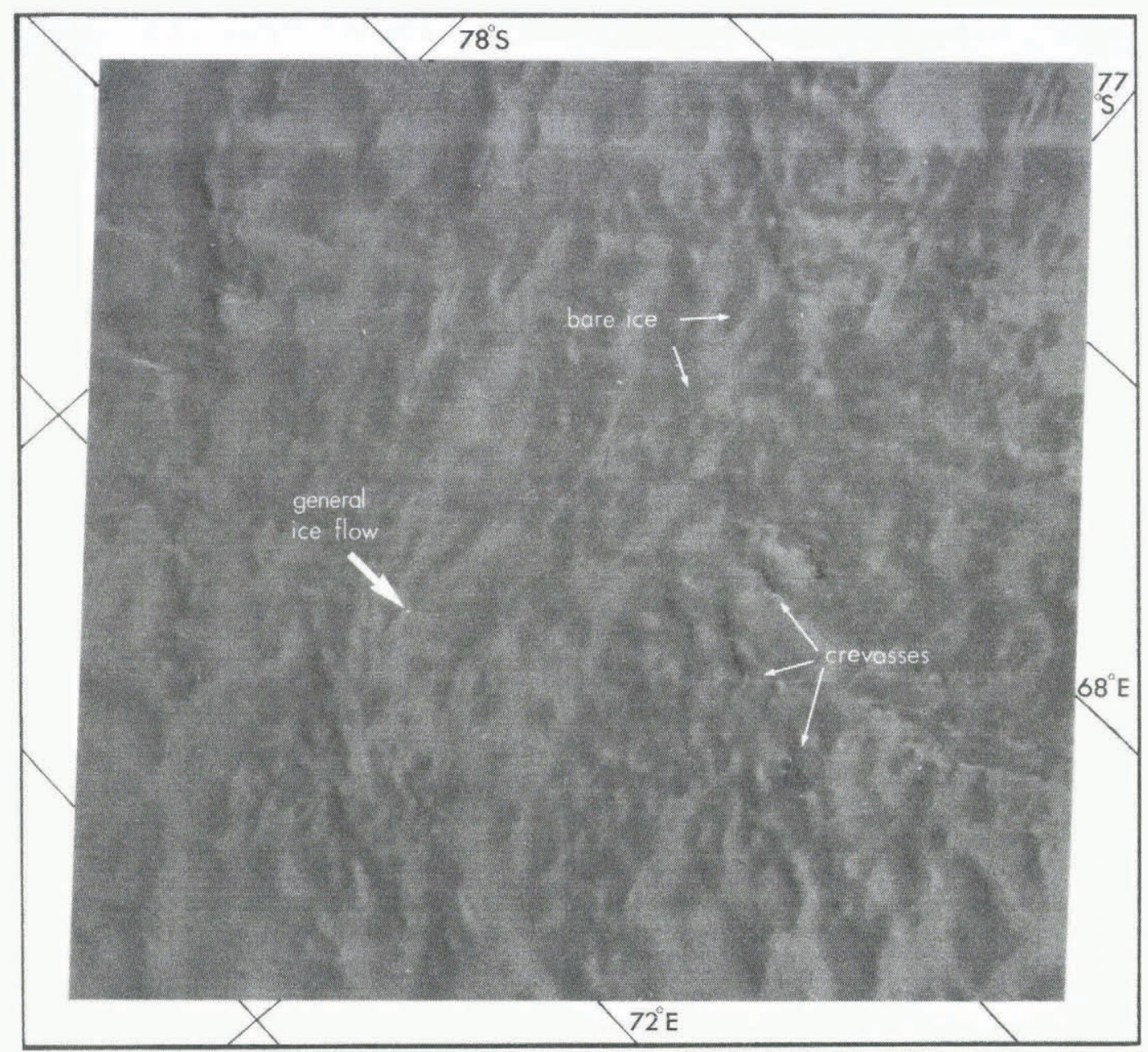

Fig. 2. Band 7 Landsat MSS image centred at lat. $76^{\circ} 15^{\prime} S$., long. $68^{\circ} 18^{\prime} E$. in the region of the subglacial Gamburtsev Mountains. Patches of bare ice (darker tones) can be seen as well as surface undulations and crevassed areas. Sun angle is $21^{\circ}$. Path 126, row 115. 1479-02223. 